\title{
Awareness, Recognition, and Response to Stroke among the General Public-An Observational Study
}

\author{
Sai Sirisha ${ }^{1}$ Sireesha Jala ${ }^{2}$ Sudhindra Vooturi ${ }^{2}$ Praveen Kumar Yada ${ }^{2}$ Subhash Kaul ${ }^{2}$ \\ ${ }^{1}$ School of Medicine, Amrita Institute of Medical Sciences, Kochi, \\ Kerala, India \\ 2 Department of Neurology, Krishna Institute of Medical Sciences, \\ Address for correspondence Subhash Kaul, DM, Department of \\ Neurology, Krishna Institute of Medical Sciences, Secunderabad \\ 500003, Telangana, India (e-mail: subashkaul@hotmail.com).
} Secunderabad, Telangana, India

J Neurosci Rural Pract 2021;12:704-710.

\begin{abstract}
Objective To evaluate awareness and response to stroke among the general public. Materials and Methods In this prospective, observational study, self-reported stroke awareness questionnaire was administered in 2000 consecutive participants who visited outpatient clinic of a tertiary care hospital. For data analysis, comparison included for awareness of stroke and response in case of stroke.

Results The average age of the study participants was $39.64 \pm 15.55$ (17-85), with 651(32.6\%) women. Among the respondents, 786(39.3\%) participants mentioned stroke as blood clot in the brain; $268(13.4 \%)$ stated it as brain hemorrhage. Awareness of stroke was higher in people in cities $(71.0 \mathrm{vs.} 8.5 \% ; p<0.001)$ and graduates $(75.3 \mathrm{vs.}$ $60.9 \% ; p<0.001)$ or knew a family member or friend who had stroke $(42.7$ vs. $30.4 \%$; $p<0.001)$. Most commonly recognized risk factors included stress $(1,152 ; 57.6 \%)$ and hypertension $(1,148 ; 57.4 \%)$. Most identified warning sign was weakness of one side of body $(807 ; 40.4 \%)$ and speech impairment $(658 ; 32.9 \%)$. Participants who were aware of stroke knew a greater number of risk factors $(3.75 \pm 2.88$ vs. $2.45 \pm 2.66 ; p<0.001)$ and warning signs $(2.85 \pm 2.25$ vs. $1.49 \pm 1.41 ; p<0.001)$. Among 1,138 participants who were aware of stroke, $166(14.6 \%)$ participants knew one correct response in case

Keywords

- stroke

- awareness

- risk factors

- warning signs

- response of a stroke, either call a doctor ( 49.3 vs. $35.0 \% ; p<0.001$ ) or call an ambulance (41.1 vs. $34.9 \% ; p=0.055)$. Participants who knew one correct response to stroke had at least a family member/friend who had stroke (44.1 vs. $34.3 \% ; p<0.022)$.

Conclusion We report that among $56.9 \%$ of the participants who were aware of stroke most could not name more than four risk factors or three warning signs of stroke. Only $14.6 \%$ of those aware of stroke knew appropriate response to stroke.
\end{abstract}

\section{Introduction}

Stroke is a major neurological, noncommunicable disease, and the third most common cause of mortality and a significant

published online September 23, 2021
DOI https://doi.org/

$10.1055 / \mathrm{s}-0041-1735822$ ISSN 0976-3147. cause of adult disability across the globe. ${ }^{1}$ In India, the incidence of stroke is $\sim 1.5$ persons per 1000 population and ranks third for mortality due to stroke. ${ }^{1}$ Importantly, $12 \%$ of all strokes occur in population younger than 40 years of age. ${ }^{1}$ (c) 2021. Association for Helping Neurosurgical Sick People. All rights reserved.

This is an open access article published by Thieme under the terms of the Creative Commons Attribution-NonDerivative-NonCommercial-License, permitting copying and reproduction so long as the original work is given appropriate credit. Contents may not be used for commercial purposes, or adapted, remixed, transformed or built upon. (https://creativecommons.org/ licenses/by-nc-nd/4.0/)

Thieme Medical and Scientific Publishers Pvt. Ltd., A-12, 2nd Floor, Sector 2, Noida-201301 UP, India 
Disability due to stroke is attributed to compromised functional abilities, cognitive impairment, mood changes, and resultant reduced efficiency at work. ${ }^{1-9}$ Not only does stroke influence the patients; nearly $70 \%$ of care-giver of stroke patients report physical and mental stress. ${ }^{10}$ Therefore, stroke is a disease of immense public health importance with economic and social consequences. ${ }^{11}$

The most crucial predictor of outcome of treatment of stroke is the time period (often called golden time) between ictus and onset of treatment. If recognized early and managed optimally, acute paralysis in stroke can be reversed. ${ }^{12,13}$ Prompt access to medical services after noticing the initial symptoms may increase the chances of a favorable outcome. ${ }^{12,13}$ According to a survey in Ireland, less than half of the older adults were able to recognize the symptoms and warning signs of stroke. ${ }^{14,15}$ Studies from India reported poor awareness of stroke among the population, where the respondents could not even identify the organ affected in stroke. ${ }^{16}$ Lack of knowledge of warning signs of stroke and inadequate emergency response often lead to delays in delivery medical/emergency care within the golden hour. ${ }^{17}$

However, knowledge of immediate action that is necessary in dealing with a stroke patient can reduce both mortality and morbidity among stroke patients by preventing delay in hospitalization. ${ }^{18}$ Low stroke awareness limits acute stroke care in high-risk populations and makes effective early treatment difficult. ${ }^{19}$ The success of primary preventive measures and timely medical attention immediately following a stroke is influenced by the public knowledge and perception of stroke and its warning signs. ${ }^{14,20} \mathrm{Few}$ recent studies have demonstrated that awareness about stroke may not always translate into efficient response in case of a stroke. ${ }^{21,22}$ Therefore, quantifying how many of those aware about stroke can respond to stroke may be essential to formulate public awareness programs.

It is well established that other than genetic etiologies, stroke is a preventable disease. ${ }^{23,24}$ Accurate knowledge of stroke risk factors and warning signs, right attitude, and proper practices of stroke prevention are shown to reduce the incidence of stroke. ${ }^{23}$ In India and other developing countries, an alarming increase in the incidence of stroke has been observed owing to an increased life span with rising trends of hypertension, diabetes, smoking, and stress in daily life. ${ }^{25}$ Prevention can be achieved through knowledge and awareness of risk factors and warning signs. However, very little is known about the awareness of risk factors of stroke in general population.

The present study was aimed to document the awareness and knowledge of stroke (risk factors, warning signs, and response to stroke) in patients and people who accompanied them to a tertiary care center.

\section{Materials and Methods}

In this prospective observation study, self-reported stroke awareness questionnaire was administered in 2000 consecutive participants who visited the outpatient clinic of a tertiary care hospital from September 2018 to March 2019. All partic- ipants aged 18 years and above who gave consent to participate in the study after being approached by the research team were included in the study. Persons below 18 years of age, those with linguistic or cognitive inability, and failure to obtain written consent formed exclusion criteria. The study was approved by the Institutional Ethics Committee.

The stroke awareness questionnaire developed by Hickey et $\mathrm{al}^{26}$ was adapted after translation into local languages (Hindi, Telugu). The data collected through questionnaire included demographic information, and 13 multiple-choice questions pertaining to what is stroke \& transient ischemic attack, risk factors of stroke, symptoms or warning signs of stroke, seriousness of stroke, did anyone of their near ones had stroke, first thing to do when you were having a stroke (call an ambulance or take to hospital or call a doctor was considered as appropriate response), and their idea of immediate response. The investigators intervened only to clarify a question, if required. No attempt was made to prompt the respondents by suggesting answers directly.

\section{Statistical analysis}

After confirming the homogeneity of data, all categorical variables were expressed as percentages and all continuous variables were expressed as a mean \pm standard deviation. The study population was divided into groups based on awareness of stroke. In a subanalysis, all the participants who were aware of stroke were divided into groups based on awareness of response in case of stroke. In the univariate analysis, differences between groups for continuous variables were done using independent Students' $t$-tests, whereas chi-squared test was used for categorical variables. A $p \leq 0.05$ was considered significant. Statistical Package for Social Sciences (SPSS, ver. 20.0, IBM computers, New York, United States) was used for all statistical analysis.

\section{Results}

The average age of the study participants was $39.64 \pm 15.55$ (17-85), with 651 (32.6\%) women participants.

Awareness about what stroke is: Out of the whole cohort, 823(41.2\%) participants thought stroke as heart attack, 239 (12.0\%) reported that they do not know what stroke is. Among the respondents, 786 (39.3\%) participants correctly mentioned stroke as blood clot in the brain; 268 (13.4\%) stated it as brain hemorrhage, while 275 (13.75\%) people mentioned it as some condition affecting brain. Additionally, $333(16.65 \%)$ people mentioned it as a circulation problem in brain, whereas 165 (8.25\%) people mentioned stroke as seizures. Significantly a greater number of people who reside in cities ( 71.0 vs. $58.5 \% ; p<0.001$ ) were aware about stroke (-Table 1). Similarly, awareness of stroke was higher in participants who were graduates (75.3 vs. 60.9\%; $p<0.001$ ) or knew a family member or friend who had stroke (42.7 vs. $30.4 \% ; p<0.001$ ). Importantly, awareness of the organ affected in stroke was also higher in those who were aware of stroke (-Table $\mathbf{2}$ ).

Awareness about risk factors for stroke: A total of 1,928 (96.4\%) participants spontaneously recalled at least one risk 
Table 1 Comparison between groups for sociodemographics $(n=2,000)$

\begin{tabular}{|c|c|c|c|}
\hline Variable & Not aware of stroke $(n=862)$ & Aware of stroke $(n=1,138)$ & $p$-Value \\
\hline Age (y) & $39.65 \pm 16.20$ & $39.63 \pm 15.12$ & 0.983 \\
\hline Women (\%) & $278(32.3 \%)$ & $373(32.8 \%)$ & 0.810 \\
\hline Resides in city (\%) & $504(58.5 \%)$ & $808(71.0 \%)$ & $<0.001$ \\
\hline Married (\%) & $590(68.4 \%)$ & $821(72.1 \%)$ & 0.075 \\
\hline Graduate (\%) & $525(60.9 \%)$ & $857(75.3 \%)$ & $<0.001$ \\
\hline Employed (\%) & $480(55.7 \%)$ & $737(64.8 \%)$ & $<0.001$ \\
\hline Family/friend with stroke (\%) & $262(30.4 \%)$ & $486(42.7 \%)$ & $<0.001$ \\
\hline \multicolumn{4}{|l|}{ Seriousness of stroke } \\
\hline Not very serious (\%) & $21(2.4 \%)$ & $29(2.5 \%)$ & 1.000 \\
\hline Quite serious (\%) & $90(10.4 \%)$ & $139(12.2 \%)$ & 0.229 \\
\hline Very serious (\%) & $294(34.1 \%)$ & $386(33.9 \%)$ & 0.962 \\
\hline Extremely serious (\%) & $327(41.5 \%)$ & $461(40.5 \%)$ & 0.951 \\
\hline Worst imaginable (\%) & $138(16.0 \%)$ & $181(15.9 \%)$ & 0.951 \\
\hline
\end{tabular}

Table 2 Comparison between groups for understanding of what is stroke $(n=2,000)$

\begin{tabular}{|l|l|l|l|}
\hline Variable & Not aware of stroke $(\boldsymbol{n}=\mathbf{8 6 2})$ & Aware of stroke $(\boldsymbol{n}=\mathbf{1 , 1 3 8 )}$ & $\boldsymbol{p}$-Value \\
\hline Blood clot in brain (\%) & $3(0.3 \%)$ & $765(67.2 \%)$ & $<0.001$ \\
\hline Brain hemorrhage (\%) & $0(0.0 \%)$ & $268(23.6 \%)$ & $<0.001$ \\
\hline Condition that affects brain (\%) & $1(0.1 \%)$ & $274(24.1 \%)$ & $<0.001$ \\
\hline Circulation problem in Brain (\%) & $1(0.1 \%)$ & $332(29.2 \%)$ & $<0.001$ \\
\hline Heart attack (\%) & $577(66.9 \%)$ & $246(21.6 \%)$ & $<0.001$ \\
\hline Seizures (\%) & $68(7.9 \%)$ & $97(8.5 \%)$ & 0.623 \\
\hline Don't know (\%) & $235(27.3 \%)$ & $0(0.0 \%)$ & $<0.001$ \\
\hline
\end{tabular}

Note: Majority of the not aware people think that it is heart attack or they don't know at all.

factor for stroke, most frequently stress $(1,152 ; 57.6 \%)$ and hypertension $(1,148 ; 57.4 \%)$. Among the other risk factors identified, 727 participants (36.35) considered high cholesterol as a risk factor, 530 (26.5\%) participants considered smoking, and 544 participants (27.2\%) reported diabetes as a risk factor. Among other factors, 647 (32.35) participants responded obesity, and 566 (28.3\%) participants thought alcohol consumption as a risk factor for stroke. However, $430(21.5 \%)$ participants reported lack of exercise and 317 participants $(15.85 \%)$ considered increasing age as a risk factor for stroke. On the contrary, 177 (8.85\%) participants did not know a risk factor for stroke. Participants who were aware of stroke knew a greater number of risk factors of stroke (3.75 \pm 2.88 vs. $2.45 \pm 2.66 ; p<0.001$; - Table 3 ).

Warning signs of stroke and response in case of stroke: Among all, 1,710 (85.5\%) participants spontaneously named at least one warning sign, most frequently weakness of one side of body ( $807 ; 40.4 \%)$, followed by speech impairment (658; 32.9\%), and dizziness (486; $24.3 \%)$. Out of entire study population, 748 people knew someone with stroke. Participants who were aware of stroke knew a greater number of warning signs than those who were not aware $(2.85 \pm 2.25$ vs. $1.49 \pm 1.41 ; p<0.001 ;$ - Table 4$)$.

Among those interviewed, 163(8.2\%) participants did not know how to respond in case a person had stroke. A greater number of participants who were aware of stroke knew how to respond in case of a stroke, call a doctor (49.3 vs. $35.0 \%$; $p<0.001$ ), or take / drive the person to a hospital (33.6 vs. $23.2 \% ; p<0.001$ ) or call an ambulance (41.1 vs. $34.9 \%$; $p=0.055$; - Fig. 1).

Among the 1138 participants who had awareness of stroke, only 166 (14.6\%) knew appropriate response in case of a stroke. On comparison between these 166 participants (who knew at least one correct response) to the rest of the group, knowing one correct response to stroke was related to having at least a family member/friend who had stroke (44.1 vs. $34.3 \%$; $p<0.022 ;$ - Table 5).

\section{Discussion}

In the current study, we evaluated the awareness of what stroke is, risk factors, and warning signs of stroke in a 
Table 3 Comparison between groups for risk factors of stroke $(n=2,000)$

\begin{tabular}{|l|l|l|l|}
\hline Variable & Not aware of stroke $(\boldsymbol{n}=862)$ & Aware of stroke $(\boldsymbol{n}=1,138)$ & $p$-Value \\
\hline Stress (\%) & $419(48.6 \%)$ & $729(64.1 \%)$ & $<0.001$ \\
\hline Hypertension (\%) & $384(44.5 \%)$ & $768(67.5 \%)$ & $<0.001$ \\
\hline Dyslipidemia (\%) & $292(33.9 \%)$ & $435(38.2 \%)$ & 0.049 \\
\hline Smoking (\%) & $155(18.0 \%)$ & $375(33.0 \%)$ & $<0.001$ \\
\hline Diabetes (\%) & $158(18.3 \%)$ & $386(33.9 \%)$ & $<0.001$ \\
\hline Obesity (\%) & $238(27.6 \%)$ & $409(35.9 \%)$ & $<0.001$ \\
\hline Alcoholism (\%) & $176(20.4 \%)$ & $380(33.4 \%)$ & $<0.001$ \\
\hline Physical inactivity (\%) & $137(15.9 \%)$ & $293(25.7 \%)$ & $<0.001$ \\
\hline Aging (\%) & $74(8.6 \%)$ & $243(21.4 \%)$ & $<0.001$ \\
\hline Family history (\%) & $78(9.0 \%)$ & $245(21.5 \%)$ & $<0.001$ \\
\hline Don't know (\%) & $135(15.7 \%)$ & $32(3.7 \%)$ & $<0.001$ \\
\hline No. of risk factors known & $2.45 \pm 2.26$ & & $<0.001$ \\
\hline
\end{tabular}

Table 4 Comparison between groups for warning signs of stroke $(n=2,000)$

\begin{tabular}{|l|l|l|l|}
\hline Variable & Not aware of stroke $(\boldsymbol{n}=862)$ & Aware of stroke $(\boldsymbol{n}=1,138)$ & $\boldsymbol{p}$-Value \\
\hline Dizziness (\%) & $141(16.4 \%)$ & $348(30.6 \%)$ & $<0.001$ \\
\hline Sudden confusion (\%) & $89(10.3 \%)$ & $286(25.1 \%)$ & $<0.001$ \\
\hline Severe headache (\%) & $83(9.6 \%)$ & $294(25.8 \%)$ & $<0.001$ \\
\hline Vision problem (\%) & $38(4.4 \%)$ & $213(18.7 \%)$ & $<0.001$ \\
\hline Slurred speech (\%) & $181(21.0 \%)$ & $477(41.9 \%)$ & $<0.001$ \\
\hline Weakness of one-side of body (\%) & $262(30.4 \%)$ & $545(47.9 \%)$ & $<0.001$ \\
\hline Facial weakness (\%) & $55(6.4 \%)$ & $258(22.7 \%)$ & $<0.001$ \\
\hline Numbness (\%) & $236(27.4 \%)$ & $504(44.3 \%)$ & $<0.001$ \\
\hline Do not know (\%) & $211(24.5 \%)$ & $79(6.9 \%)$ & $<0.001$ \\
\hline No. of warning signs known & $1.49 \pm 1.41$ & $2.85 \pm 2.25$ & $<0.001$ \\
\hline
\end{tabular}

\section{Comparison for first response to stroke}

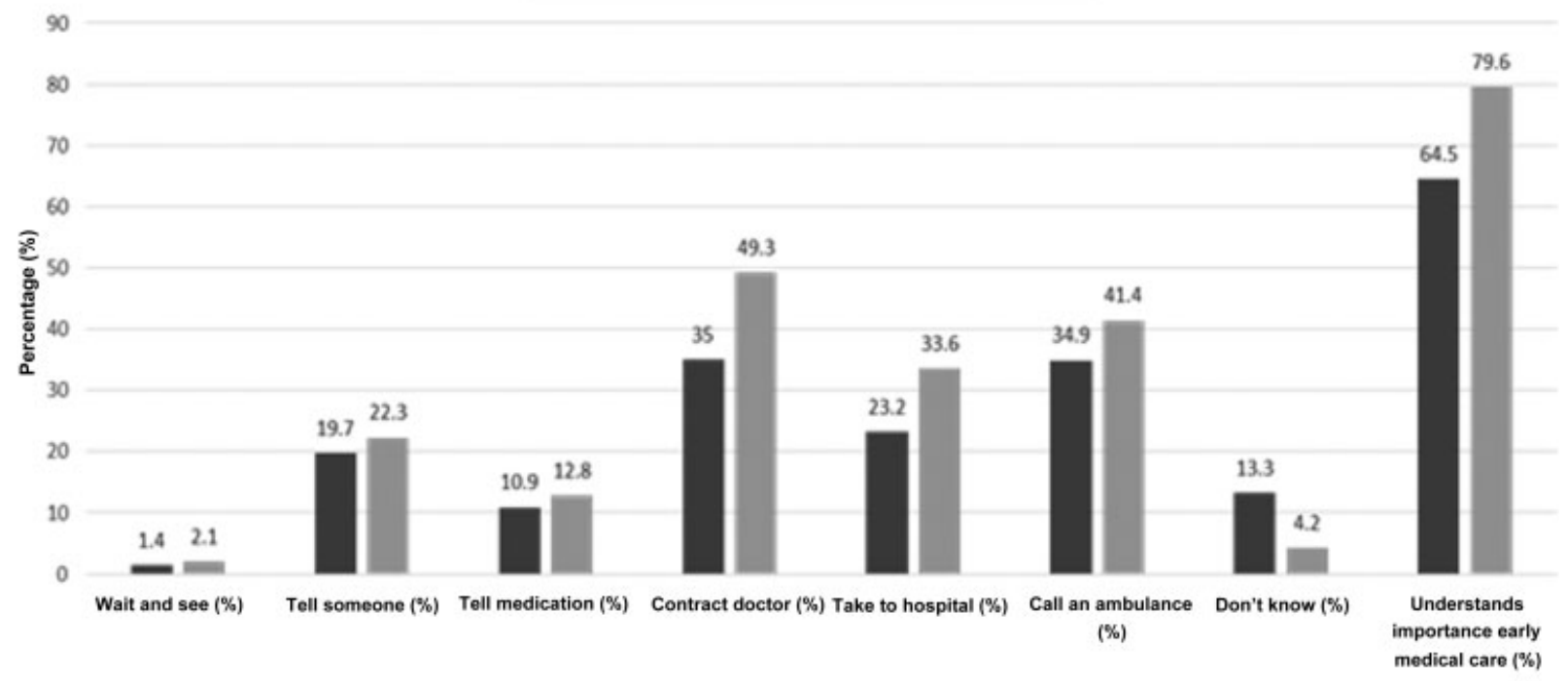

not-aware of stroke = Aware of stroke

Fig. 1 Comparison for first response to stroke. 
Stroke Awareness and Response in Case of a Stroke Sirisha et al.

Table 5 Comparison for response to stroke among those aware of stroke $(n=1,138)$

\begin{tabular}{|c|c|c|c|}
\hline Variable & Appropriate response $(n=166)$ & Inappropriate response $(n=972)$ & $p$-Value \\
\hline Age $(y)$ & $39.21 \pm 14.73$ & $39.70 \pm 15.20$ & 0.699 \\
\hline Women (\%) & 52 (31.3\%) & $321(33.0 \%)$ & 0.721 \\
\hline \multicolumn{4}{|l|}{ Type of residence } \\
\hline City (\%) & 116 (69.9\%) & $692(71.2 \%)$ & \multirow[t]{3}{*}{0.921} \\
\hline Town (\%) & $33(19.9 \%)$ & $189(19.4 \%)$ & \\
\hline Village (\%) & $17(10.2 \%)$ & $91(9.4 \%)$ & \\
\hline \multicolumn{4}{|l|}{ Education } \\
\hline Uneducated (\%) & $3(1.8 \%)$ & $32(3.3 \%)$ & \multirow[t]{5}{*}{0.605} \\
\hline Matriculation (\%) & $20(12.0 \%)$ & $110(11.3 \%)$ & \\
\hline Intermediate (\%) & $20(12.0 \%)$ & $96(9.9 \%)$ & \\
\hline Graduate (\%) & $78(47.0 \%)$ & $431(44.3 \%)$ & \\
\hline Postgraduate (\%) & $45(27.1 \%)$ & $303(31.2 \%)$ & \\
\hline \multicolumn{4}{|l|}{ Occupation } \\
\hline Unemployed (\%) & $52(31.3 \%)$ & $243(25.0 \%)$ & \multirow[t]{4}{*}{0.324} \\
\hline Self-employed (\%) & $32(19.3 \%)$ & $191(19.7 \%)$ & \\
\hline Employed (\%) & $66(39.8 \%)$ & $448(46.1 \%)$ & \\
\hline Retired (\%) & $16(9.6 \%)$ & $90(9.3 \%)$ & \\
\hline Friend/family who had stroke (\%) & $57(34.3 \%)$ & $429(44.1 \%)$ & 0.022 \\
\hline
\end{tabular}

relatively large cohort of general population visiting a tertiary care center. We report that $56.9 \%$ of the participants were aware of what stroke is. Among those who are aware of stroke, most of the participants could not name more than four risk factors and three warning signs of stroke. Importantly, only $14.6 \%$ of those aware of stroke knew appropriate response to in case of a stroke. Knowing a friend or family person who had stroke is associated with appropriate response to stroke.

Awareness of stroke among 56.9\% in the current study is marginally higher than the awareness reported in previous studies from India and Western population. ${ }^{15,16,22,26-33}$ This is probably because of the participants of the current study constituted those who visited a tertiary referral center or those from urban/city population and therefore perhaps have a better understanding of stroke. Similarly, nearly two-thirds of participants in our study identified stress and hypertension as the leading risk factors of stroke; this awareness of risk factors is higher than the $50 \%$ reported by previous studies. ${ }^{15,16,26,29,32,34-37}$ However, the mean number of risk factors identified in our study did not differ from existing literature.

The proportion of awareness of warning signs of stroke (like weakness of one side of the body, slurring of speech, deviation of mouth) in the current study is similar to those reported previously. ${ }^{29,33}$ In previous studies, the response to stroke was evaluated in the entire cohort of participants who were aware and those not aware of stroke. One of the novelties of the current study was to evaluate factors affecting response in case of stroke only among participants aware of stroke. We observed that only $14.6 \%$ of those aware of stroke knew appropriate response in case of stroke and knowing a friend or family member who had a stroke increases the odds that the response is appropriate. Perhaps, awareness programs should not only aim at improving knowledge about what stroke is but also educate people about what to do in case of a stroke.

On reviewing the literature about effectiveness of public awareness programs, Lecouturier et $\mathrm{al}^{38}$ reported that public awareness campaigns significantly increase awareness of symptoms, but not emergency response, as evaluated by reduced time of presentation to hospital. Moreover, it is previously known that knowledge of stroke symptoms may not be associated with the intention to seek emergency services. ${ }^{14,36,39}$ These observations are probably because of a "belief that symptoms will subside." ${ }^{40}$ Therefore, a robust awareness program should also educate population about importance of seeking medical services at the earliest. Mass media interventions although have the potential to reach large populations in health-related areas, the impact on behavior change has been small to moderate. ${ }^{41}$ Perhaps, the role of physicians and health personnel is, therefore, of enormous importance. In an enormous mismatch of doctorpatient ratio in developing countries, robust studies are required to ascertain the extent of involvement of healthcare personnel needed in spreading the awareness.

Strengths and limitations: The current study is one of the largest of its kind, conducted in South India. With a reported prevalence of awareness of stroke at nearly $51.2 \%$, our study required only 1512 participants at a confidence level of $99.99 \%$, but 500 additional participants were recruited to account for design effect. However, a potential limitation 
could be that this is a single-center study where the participants were consecutive visitors to a tertiary referral care center and were not picked from a door-to-door community survey. However, to neutralize this bias, the participants were not just patients or their care-givers but also included visitors on other purposes to the hospital and were enrolled among outpatient visitors across all the departments with an aim to make the study sample representative of general public.

\section{Conclusion}

In this study, in a relatively large cohort of general population visiting a tertiary care center, we report that $56.9 \%$ of the participants were aware of what stroke is. Importantly, only $14.6 \%$ of those aware of stroke knew appropriate response to in case of a stroke. Knowing a friend or family person who had stroke is associated with appropriate response to stroke. Future research could study the role of robust and wellplanned awareness programs that emphasize stroke, its warning signs, response, and sequelae.

\section{Funding}

None.

\section{Conflict of Interest}

None declared.

\section{References}

1 WHO publishes definitive atlas on global heart disease and stroke epidemic. Indian J Med Sci 2004;58(09):405-406

2 Das SK, Banerjee TK. Stroke: Indian scenario. Circulation 2008; 118(25):2719-2724

3 Das SK, Banerjee TK, Biswas A, et al. A prospective communitybased study of stroke in Kolkata, India. Stroke 2007;38(03): 906-910

4 Gupta A, Pansari K, Shetty H. Post-stroke depression. Int J Clin Pract 2002;56(07):531-537

5 Gupta A, Thomas P. General perception of stroke. Knowledge of stroke is lacking. BMJ 2002;325(7360):392

6 Gupta A, Thomas P. Stroke prevention: missed opportunities? Int J Clin Pract 2002;56(05):338-341

7 Lenzi GL, Altieri M, Maestrini I. Post-stroke depression. Rev Neurol (Paris) 2008;164(10):837-840

8 Lenzi GL, Di Piero V. The role of stroke units in the subacute stage of stroke. Nat Clin Pract Neurol 2008;4(09):480-481

9 Sturm JW, Donnan GA, Dewey HM, et al. Quality of life after stroke: the North East Melbourne Stroke Incidence Study (NEMESIS). Stroke 2004;35(10):2340-2345

10 Das S, Hazra A, Ray BK, et al. Burden among stroke caregivers: results of a community-based study from Kolkata, India. Stroke 2010;41(12):2965-2968

11 Donkor ES, Owolabi MO, Bampoh P, Aspelund T, Gudnason V. Community awareness of stroke in Accra, Ghana. BMC Public Health 2014;14:196

12 Bushnell CD, Goldstein LB. Physician knowledge and practices in the evaluation of coagulopathies in stroke patients. Stroke 2002; 33(04):948-953

13 Davis S, Lees K, Donnan G. Treating the acute stroke patient as an emergency: current practices and future opportunities. Int J Clin Pract 2006;60(04):399-407
14 Jones SP, Jenkinson AJ, Leathley MJ, Watkins CL. Stroke knowledge and awareness: an integrative review of the evidence. Age Ageing 2010;39(01):11-22

15 Parahoo K, Thompson K, Cooper M, Stringer M, Ennis E, McCollam P. Stroke: awareness of the signs, symptoms and risk factors-a population-based survey. Cerebrovasc Dis 2003;16(02):134-140

16 Pandian JD, Jaison A, Deepak SS, et al. Public awareness of warning symptoms, risk factors, and treatment of stroke in northwest India. Stroke 2005;36(03):644-648

17 Oh GJ, Lee K, Kim K, Lee YH. Differences in the awareness of stroke symptoms and emergency response by occupation in the Korean general population. PLoS One 2019;14(06):e0218608

18 Srivastava AK, Prasad K. A study of factors delaying hospital arrival of patients with acute stroke. Neurol India 2001;49(03): 272-276

19 Willey JZ, Williams O, Boden-Albala B. Stroke literacy in Central Harlem: a high-risk stroke population. Neurology 2009;73(23): 1950-1956

20 Akinyemi RO, Ogah OS, Ogundipe RF, et al. Knowledge and perception of stroke amongst hospital workers in an African community. Eur J Neurol 2009;16(09):998-1003

21 Li S, Cui LY, Anderson C, et al; FAST-RIGHT Investigators and Coordinators. Barriers from calling ambulance after recognizing stroke differed in adults younger or older than 75 years old in China. BMC Neurol 2019;19(01):283

22 Li S, Cui LY, Anderson C, et al; FAST-RIGHT Investigators and Coordinators. Public awareness of stroke and the appropriate responses in China: a cross-sectional community-based study (FAST-RIGHT). Stroke 2019;50(02):455-462

23 Hankey GJ. Preventable stroke and stroke prevention. J Thromb Haemost 2005;3(08):1638-1645

24 Leys D, Deplanque D, Mounier-Vehier C, Mackowiak-Cordoliani MA, Lucas C, Bordet R. Stroke prevention: management of modifiable vascular risk factors. J Neurol 2002;249(05):507-517

25 Kaul S. Strike out stroke. Neurol India 2002;50(S1):443

26 Hickey A, Holly D, McGee H, Conroy R, Shelley E. Knowledge of stroke risk factors and warning signs in Ireland: development and application of the Stroke Awareness Questionnaire (SAQ). Int J Stroke 2012;7(04):298-306

27 Das S, Das SK. Knowledge, attitude and practice of stroke in India versus other developed and developing countries. Ann Indian Acad Neurol 2013;16(04):488-493

28 Kaddumukasa M, Kayima J, Kaddumukasa MN, et al. Knowledge, attitudes and perceptions of stroke: a cross-sectional survey in rural and urban Uganda. BMC Res Notes 2015;8:819

29 Menon B, Swaroop JJ, Deepika HKR, Conjeevaram J, Munisusmitha K. Poor awareness of stroke-a hospital-based study from South India: an urgent need for awareness programs. J Stroke Cerebrovasc Dis 2014;23(08):2091-2098

30 Sadeghi-Hokmabadi E, Vahdati SS, Rikhtegar R, Ghasempour K, Rezabakhsh A. Public knowledge of people visiting Imam Reza hospital regarding stroke symptoms and risk factors. BMC Emerg Med 2019;19(01):36

31 Sug Yoon S, Heller RF, Levi C, Wiggers J. Knowledge and perception about stroke among an Australian urban population. BMC Public Health 2001;1:14

32 Sug Yoon S, Heller RF, Levi C, Wiggers J, Fitzgerald PE. Knowledge of stroke risk factors, warning symptoms, and treatment among an Australian urban population. Stroke 2001;32(08):1926-1930

33 Pandian JD, Kalra G, Jaison A, et al. Knowledge of stroke among stroke patients and their relatives in Northwest India. Neurol India 2006;54(02):152-156, discussion 156

34 Chhabra M, Gudi SK, Rashid M, Sharma P, Sharma S, Khan HRohit 4Assessment of knowledge on risk factors, warning signs, and early treatment approaches of stroke among community adults in North India: a telephone interview survey. J Neurosci Rural Pract 2019;10(03):417-422 
710 Stroke Awareness and Response in Case of a Stroke Sirisha et al.

35 Dalal PM, Bhattacharjee M. Stroke epidemic in India: hypertension-stroke control programme is urgently needed. J Assoc Physicians India 2007;55:689-691

36 Fussman C, Rafferty AP, Lyon-Callo S, Morgenstern LB, Reeves MJ. Lack of association between stroke symptom knowledge and intent to call 911: a population-based survey. Stroke 2010;41(07):1501-1507

37 Pancioli AM, Broderick J, Kothari R, et al. Public perception of stroke warning signs and knowledge of potential risk factors. JAMA 1998;279(16):1288-1292

38 Lecouturier J, Rodgers H, Murtagh MJ, White M, Ford GA, Thomson $\mathrm{RG}$. Systematic review of mass media interventions designed to improve public recognition of stroke symptoms, emergency response and early treatment. BMC Public Health 2010;10:784

39 Lecouturier J, Murtagh MJ, Thomson RG, et al. Response to symptoms of stroke in the UK: a systematic review. BMC Health Serv Res 2010;10:157

40 Daley S, Braimah J, Sailor S, et al. Education to improve stroke awareness and emergent response. The NINDS rt-PA Stroke Study Group. J Neurosci Nurs 1997;29(06):393-396

41 Wakefield MA, Loken B, Hornik RC. Use of mass media campaigns to change health behaviour. Lancet 2010;376 (9748):1261-1271 